\title{
From Sex Toys to Pleasure Objects
}

\author{
Vanessa Carpenter \\ Aalborg University \\ C. Meyers Vænge 15, \\ 2450 Copenhagen, \\ Denmark \\ vjc@create.aau.dk
}

\author{
Sarah Homewood \\ IT University of Copenhagen \\ Rued Langgaards Vej, 7, \\ Copenhagen \\ Denmark \\ shom@itu.dk
}

\author{
Majken Overgaard \\ Catch Centre for Art and \\ Technology \\ Allegade 2, 3000, \\ Helsingør \\ Denmark \\ majkenovergaard@gmail.com
}

\author{
Stefanie Wuschitz \\ Academy of Fine Arts \\ Vienna, Mz* Baltazar's \\ Laboratory \\ 1090 Wien, Augasse 2-6 \\ s.wuschitz@akbild.ac.at
}

\begin{abstract}
This research works against essentializing notions of sexuality, gender and pleasure within the design of sex objects through proposing and developing the design of DIY kits suitable to manipulate and customise what objects designed for sex mean for the individual and their role in society in relation to gender and sexuality. This paper outlines a series of participatory workshops where artists and designers were invited to contribute to the design of the DIY kits. Three artistic works emerge from the workshops as beta DIY kits, alongside a future work of a DIY electronics kit and an online collaborative platform. These workshops led to the shift of focus from sex objects to pleasure objects.
\end{abstract}

Sex, Feminism, Participation, Pleasure, DIY, Kits, Future Technologies, Future Pleasure Objects

\section{INTRODUCTION}

The design, form and function of technologies designed for sex and pleasure communicate societal norms, taboos and cultural beliefs around the topic (Bardzell and Bardzell, 2011). This research employs a feminist lens to challenge the design of sex objects that dictates what kind of sex we should be having. For example, the primacy of phallic sex toys for women dictate a heterosexual notion of sexuality. We propose that many devices designed for sex perpetuate universalizing and essentializing ideas of sex acts, sexuality and gender. We explore the concept for an alternative design in the form of a DIY kit. Instead of finding the answer to the question of "what people really want" in terms of sex toys, we propose giving users the tools to get creative and find out for themselves.

As $\mathrm{HCl}$ moves into its third wave (Bødker, 2006), humanistic topics and human concerns within the design of technology for our daily lives have emerged. Pleasure as a measure of $\mathrm{HCl}$ is being increasingly popular (Huta and Ryan, 2010, Hassenzahl et al, 2013, Diefenbach, Kolb and Hassenzadl, 2014, Mekler and Hornbæk, 2016) and researchers have pointed towards a focus on sex in $\mathrm{HCl}$, such as the Sex \& Bodies session at $\mathrm{CHI}, 2011$ (Bardzell and Bardzell, 2011) and (Eaglin and Bardzell, 2011) or the article by Blythe and Jones (2004) encouraging more research into this area. Homewood and Heyer, 2017 explore what the digitalisation of contraceptive methods means for rituals around sex and parenthood.

The overall ambition of this research is to advance the vision of what sex objects could be and do in order to help mediate autonomous and non-binary articulations of desire and the machine. We do this through holding participatory workshops, where invited participants can explore and experiment together in developing a DIY kit. We are exploring both currently available technologies and speculating about what we would like to have at our disposal in the future. Culminating from the workshops, we present three artistic works created under the title of "Future Pleasure Objects" and conclude with a future works section, speculating on how communities, artists, technologists, and politics will create and relate to pleasure objects in a postporn reality.

Alongside the concept of the DIY kit, including the three example kits: the artistic works, a third contribution of this research to the field of $\mathrm{HCl}$ is the discussion based on the shift within the story of this research from "sex objects" to "pleasure objects". This is based upon observations from the workshops and appears to reflect a change of attitude in participants and organisers in regards to sex once the boundaries of the design of sex toys are breached and alternative materialities and forms are possible. 


\section{METHODOLOGY}

\subsection{Feminism}

To re-imagine what sex means to us through designing alternative sex objects is to trouble norms in society. Our motivation behind this is inspired by a feminist perspective. We are strongly influenced by Donna Haraway's social constructionist approach to science, and therefore embrace situated knowledge generated in the workshops (Haraway, 1991). Haraway sees objects as 'boundary projects', boundaries manifest through social interaction. This is our motivation behind adopting a design-based method, where the objects themselves trouble, reimagine, and propose alternative boundaries in and of themselves.

Third wave feminism is often associated with a sexpositive and queer approach to feminist discourse, art and activism. This approach tries to avoid the mistakes of second wave feminism, which was critiqued for having painfully replicated racism and colonialism (Ahmed, 2017), as it only considered and benefited white middle class heterosexual women, while the feminist struggle of authors, artists and activists not falling into these norms were rendered invisible. It was also critiqued for focusing too much on the risks of sexuality (abuse, abortion, rape), instead of taking back our bodies as autonomous sites for pleasure. Third wave feminism therefore tries to approach issues intersectionality, being aware of all intersecting discriminations a person has to deal with (for example racism intersecting with sexism, heteronormativism intersecting with classism) (Mohanty, 2003, p.7). And at the same time encouraging ownership of bodies, and embracing sensuality, sexuality, lust and love.

In third wave feminism 'Gender' is not believed to be binary - male or female - but instead being enacted and performed by a person in every moment of life. Hence, gender performance is not equal to biological sex or to sexual orientation. This kind of questioning and unsettling of representationalist politics (Barad, 2012) enables new artistic experiments to emerge. They allow artists to construct authentic ways of feeling, sensing, touching, relating, enjoying, caring, desiring based on their own diverse and fragmented experiences. New technologies play a crucial role in enabling these experiments, pushing the limits of cognition and merging borders between human and nonhuman. Queering and constructing intimacy through pleasure objects this way becomes a form of worldmaking.

In de-constructing and re-constructing the design of sex toys into a DIY kit, we create new, more moveable boundaries around how sex objects dictate what kind of sex we have and what sex means to us as individuals. We therefore argue that feminism is our methodology, and follow Bardzell, (2010) in advocating for participatory methods when designing for plurality and inclusive designs.

\subsection{Design Anthropology}

Design anthropology (Gunn, Otto \& Smith, 2013) was chosen as the vehicle for this research due to the possibilities it allows for designing for the future through a critical investigation of existing concepts around the body and technology. Design is oriented towards the future while anthropology provide contextual knowledge and allows for theorizing the usage. Design anthropology was chosen because it allows us to combine observations, iterative actions and reflections throughout the development process.

Rather than making statements about what is, design is concerned with creating what might be. (Gaver, 2012). In this work, we invite artists and researchers to collectively discuss, debate and create, wherein each iteration, whether it be a workshop or an artefact, generates new formulations of what future pleasure objects might entail, and broadens the scope of what is possible while simultaneously creating limitations on what we mean by future pleasure objects.

\section{RELATED WORK}

An important aspect of design anthropology is to gain an understanding of the current culture in order to create something new (Gunn, Otto \& Smith, 2013). Therefore, as preparation for the workshops existing artistic and technology projects relating to the body were studied in order to provide a researchbased framework.

\subsection{Contemporary Art and the Body}

Contemporary art since the 1960s has used the body as a canvas and as a means of expression. Over the years, artists increasingly claimed ownership over their body and counteracted various forms of external appropriations. To limit our field of research we have focused on works of art affiliated with technology and the DIY culture and include artists who apply scientific knowledge to influence their body in a subtle and subversive manner. For example in Mary Magic, an 'estrofemlab' helps to extract estrogen from body fluids to increase the estrogen level and show the 'Micro Performativity of Sex Hormones' (Tsang, 2016). Alternatively, Heather Dewey-Hagborg, who collects strangers' DNA such as hair or skin particles in public space to reconstruct their identity (Dewey-Hagborg, 2014). And the artist group Pechblenda, when they develop first aid gynecological tools to 'decolonize' the female body (Gynepunk) (Pechblenda, 2015). They 
all approach intimate and private - for others, invisible or hidden - body parts, functions, sensations, circles and inner dynamics. Giulia Tomasello follows the same strategy of subtle intervention when she hides DIY biotechnologically treated panty liners in female underwear (Tomasello, 2018) in order to prevent vaginal infections, emphasizing the immense impact of consistently present microbes and bacteria on our body.

These projects embrace the body, inhabit it consciously and seize it as site of artistic intervention to increase well-being, health or pleasure. This ambition is usually monopolized by industries such as the pharma industry. This kind of 'taking back the body' results in a curious exploration on the intersection of art and science. Our project aligns with these efforts in the sense that we follow similar strategies, encourage similar DIY and citizen science practices and share similar perspectives.

\section{2. $\mathrm{HCl}$ and the Body}

The very nature of Human Computer Interaction $(\mathrm{HCl})$ and Interaction Design is to explore the human in relation to technology and vice versa, and there exist a subset of fields relating specifically to exploration of the body and bodily engagement. Höök et al, (2018) in their work on soma-based design, introduce and explore somaesthetics (the perception of the body and experiences therein) and describe how user experience can be described as "a living, purposive, sentient, perceptive body or bodily subjectivity engaging in meaning-making processes" (Höök et al, (2018)). With this lens we look towards related technologies in this work. Núñez-Pacheco and Loke explore how wearables acting on the body (in their case, a vibration motor encased in a scarf) can facilitate a dialogue between "soma and intellect" (Núñez-Pacheco and Loke, 2017). This points to how technology, acting on the body, can be a facilitator of an experience, instead of transmitting digital information (such as a notification). In the Skintillates project, extremely thin circuits are built into temporary tattoos, demonstrating how skin can be used as an interface (Lo et al, 2016). Haptics are used extensively in bodily interaction and not always for transmission of digital information. The Hedonic Haptics player (Boer, Vallgårda and Cahill, 2017) is a device which is worn on the body and transmits vibrotactile patterns as a form of experience. In "How Bodies Matter: Five Themes for Interaction Design", Klemmer, Hartmann and Takayama (2006) explain, "One of the most powerful human capabilities relevant to designers is the intimate incorporation of an artifact into bodily practice to the point where people perceive that artifact as an extension of themselves". It is in this framing that we seek to create future pleasure objects, devices which are still devices with electronics, sensors, actuators, but which become an extension of the person, helping them to explore their bodies, and understand what pleasure means to them.

\section{DIY CULTURE AND KITS TO WORK/REWORK YOUR BODY}

DIY (Do-It-Yourself) cultures contain many subcultures. Some of these subcultures focus on the creation of kits, where you can create something following instructions, and use a set of modular elements which are provided in a kit. A simple example of this might be a DIY-craft kit, or food based, such as make your own jam, or electronics based. Examples of DIY kits exist extensively within academia, such as a DIY paper machines kit (Oh et al, 2017), a DIY circuitry kit (Kim, 2013) or a DIY silicon soft circuit kit (Nagels et al, 2018). When we conducted desktop research investigating onmarket DIY kits and the body, we found that current available technologies are primarily focusing on two parameters: penetration and vibration. Users can mold various phallic shaped objects and equip them with vibrators or use existing objects such as fruit to create their own vibrators, supported by opensource device platforms such as OSSex (Comingle, 2018). While these types of kits and platform do offer a craft-like approach to constructing an artifact, we felt there was an opportunity for expansion into new domains, which are explorative rather than goaloriented.

We were particularly interested in what a kit of electronics might contain if artists were to design one for people to facilitate their own pleasure. Electronic kits are popular, many can be found on sites such as SparkFun (Sparkfun Kits, 2018), an electronic supplier and community for people developing such kits which typically include all the tools to build a functional device. We also gained inspiration from Perner-Wilson's "Kit of no parts" (Perner-Wilson, Buechley and Satomi, 2010) wherein she introduces a set of craft materials which act as catalysts for creative exploration of material interaction without adhering to a typical "build-this" kit such as the kind found at Sparkfun. Similarly, LittleBits offers kits which offer an exploratory experience, their basic kits offer (mainly children) the opportunity to experiment with electronics, and they also offer derivative kits such as their sound/synth kit: (LittleBits Synth, 2018).

We imagine a series of DIY kits co-created with artist, offering a concept such as those presented in the section "Platform for artistic pleasure kits". We are currently developing our own kit, the Kit Zero: a barebones kit which offers a series of vibration motors with multiple types of input. This kit investigates what the vibrator actually is, what 
technological boundaries there are and how vibration can be connected to our body in new ways and represents an alternative to binary pleasure objects; with this kit, users can explore various types of vibration as output and various types of input. As an example, a person might like to explore how stroking a stone, fabric, or moving hands through water could control a vibrator. The input methods are limited only by imagination and the output can be explored, in this first phase, via 4 different styles and sizes of motors.

\section{FROM SEX TOYS TO PLEASURE OBJECTS}

\subsection{The workshops}

The workshops are based on a hacktivist, open source approach where knowledge is produced collectively. Furthermore, our project relies on feminist hacking as an art-based research practice involving an intensive knowledge-sharing process, structured around breaking with feminine gender scripts, transgressing gender norms and embracing technological challenges. Feminist hacking is about developing artistic technology, based on open hardware, from a queer and female perspective.

We wanted to work out of safe spaces; an intentional environment where knowledge exchange is encouraged among participants and where we enable learning from each other to come up with new ideas and concepts. Thus, we set up the workshops in two environments in Vienna and Copenhagen which both have an emphasis on inclusion and creating safe and creative environments.

\subsection{Workshop 1: Mz* Baltazar's Lab, Vienna, 12. 2016}

In this first workshop, we knew we wanted to explicitly set the challenge to design away from phallic sex toys and instead focus on bodily engagement and exploration. Together with the founders of $\mathrm{Mz}^{*}$ Baltazar's Lab in Vienna, we sent an invite under the title Future Sexual Objects to everyone on their mailing-list. Twelve participants joined us with very different backgrounds such as medical doctors, artists, designers, hackers and people with an interest in technology and/or the body. The invite specified:

"Sex toys are often limited to being phallic in shape and having limited modes. We know there is room for improvement, but what are the possibilities for shapes and features? The overall theme of the evening will be, how can we re-invent the vibrator? The emphasis will be on discussing potential features and how various features might affect the understanding of sexuality and the relation to technology."
As we wanted to be inclusive of everyone's skills and we only had 2.5 hours at our disposal for the workshop, we did not plan for technology development, or hacking, to occur. Our aim was to investigate if people were actually interested in the subject, in sharing knowledge about the subject and if so, to start a dialogue about future joint projects

Participants were shown a presentation of images featuring different shapes, materials, technologies and ways of stimulating the body such as acupuncture and reflexology to expand their associations of bodies and technology. Following this, we held a discussion about pleasure and how participants related to technology and their bodies.

Participants exhibited surprising openness and willingness to share both what they considered problematic in relation to current technology developed for the body and ideas for potential future projects and 3 projects (described below) emerged as a result of this workshop. However, some participants indicated they would be interested in working with bodily interaction, though not sex toys. Participants were not only interested re-inventing the vibrator but rather widened the scope to encompass pleasure on a whole-body scale and expressed interest in the exploration of technology that goes beyond vaginal stimulation alone.

\section{Workshop 1: Conclusion}

As the debate focused on body and pleasure in a broader sense, the title of the project evolved to become Future Pleasure Objects. In this stream, there was significant interest in the development of DIY kits and three projects emerged from the discussions.

\subsection{Workshop 2: S-rummet, Copenhagen, 02.2017}

For the second workshop we decided on a different approach in regards to finding participants as we wanted to start prototyping kits. We invited our personal connections, including academics, artists, hackers, creatives and people from industry. We curated a diverse group to facilitate debate and designed the workshop using a group based approach wherein participants in groups debated amongst themselves. This was similar to a focus group (Bjørner, 2015, p. 73) but with more emphasis on casual debate and brainstorming than analysis of a product.

The workshop began with the same presentation as in Vienna, however, we changed the headline to Future Pleasure Objects. Afterwards we asked participants to form groups and tried to ensure there was a mix of artists, academics, hackers and others in each group. We asked groups to consider the following keywords, which were derived from the 
presentation: Material, Shape, Context, Triggers through other means (light), Surfaces, Links to external events, Portable, Shape shifting, Sound, Clothing, and Sensors. Each group created a set of mind maps noting their discussion and these are briefly presented below:

Group 1: A focus on treasure maps arose, asking about how geocaching or dead-drops might be used to convey data which could be interpreted as actuated activity in a bodily device.

Group 2: There was a distinct focus on developing products with aesthetic quality and using aesthetics as a pleasure trigger.

Group 3: An interest in sound, movement and experience was dominant in this group as they explored sound versus visuals as potential sources of pleasure.

We derived a set of common themes from the groups, namely an interest in exploring unusual ways of interacting with the body including: sound, light, data, via public activity sensing, fluids, and memories. Further, two strong themes emerged, that of the difference between public and private, and interpersonal versus personal relationships. There was significant discussion about how to engage with the world outside the bedroom, including the city, other people, landscapes, and as mentioned, public activity. Further, the topic of interpersonal interaction was also strong, participants imagined how we might interact with others to create and enjoy pleasure, without those others necessarily being a sexual or highly personal relationship.

\section{Workshop 2: Conclusion}

All groups were interested in developing kits and had many ideas for future projects. We found that this second workshop further informed our work in the development of objects designed for pleasure for the individual's body.

\subsection{Workshop 3: Vienna, 12.2017}

We returned to Vienna to have a dialogue with the artists responsible for the three projects which emerged during the first workshop. The artists are Patricia Reis and Kristin Weissenberger. Patricia Reis is a researcher who has been researching the relation between art, technology and the body (Reis, 2018). For Future Pleasure Objects she is experimenting with breath and sensation on the body. Kristin Weissenberger works with various materials, primarily ceramics. Kristing was joined by Günter Seyfried, both from Pavillon35 (2018), and they were joined by Doris Roth from [kat]alab (2018). Together, they developed a project involving ceramics and the development of a new type of hydrogel. The three projects are described in the section: Platform for Artistic Pleasure Kits.

\subsection{Summary of Workshops: Moving from idea development to a DIY Kit platform}

The workshops informed what the DIY kits might contain in relation to materials, shapes and ways of interacting. Most interestingly was a move away from silicone as a material, the desire to experiment with other types of shapes than the phallic and penetrable shape, and to develop new social ways of interacting through technology in order to achieve pleasure. We found that the technologies developed were not aimed at women or men, but focused on non-heterosexual notion of sexuality.

As a consequence of the discussion at the last workshop in Vienna we aim to develop a platform for future pleasure objects, alongside artists and hackers, who combine electronics with other mediums, interaction modalities and our physical world to enable people to explore pleasure, and ultimately themselves, and others.

\section{PLATIFORM FOR ARTISTIC PLEASURE KITS: EXPLORATIONS IN WHAT FUTURE PLEASURE OBJECTS MIGHT BE.}

As the three projects were being developed (described below), we begin to develop the idea of an online platform for artistic pleasure kits. This will take the form of a website whose aim is to become a platform wherein artists co-create the kits with those curious about non-binary pleasure objects.

We imagine a series of kits offering concepts such as the below described Ardourino, Touching you/me with my breath and Text Me, in a kit format.

The components needed to build such a device would be offered as a DIY-Kit containing the necessary elements, instructions, and importantly, suggestion to experiment and derive new experiences.

One of the first kits to be offered on this platform will be our future work, Kit Zero as described earlier in the section: DIY Culture and Kits. This website's content is owned by the artists and potential surplus is shared collectively. In this way the website becomes an experiment for future business models, where artists are recognized for being the producers of content.

The following three works are presented as beta versions of Future Pleasure Objects DIY kits: 


\subsection{Text Me}

Text Me by Patricia Reis \& Yara Bartel is a wearable device which does not rely on binary gender assumptions to operate. Instead, it focuses on the spine, where 12 vibration motors are triggered in varying patterns according to the content of text messages sent to the device. Reis and Bartel aim to facilitate a digital translation between body and mind, triggering body sensations via text message.

\subsection{Touching you/me with my breath}
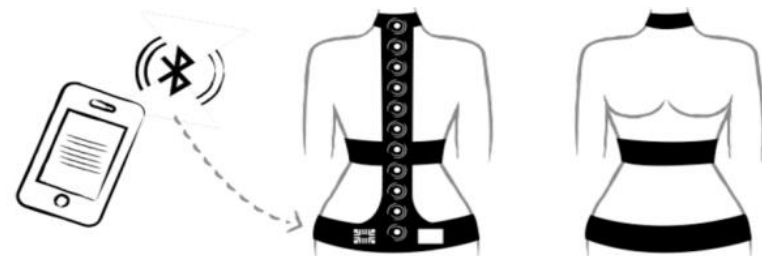

Figure 1: Text Me

Touching you/me with my breath by Patricia Reis is an interactive, non-visual device which aims to bring people together via breath, or allow someone to explore their own sense of pleasure via their own breath. As breath is sensed, a microcontroller translates the rhythm, intensity and humidity of the breath into vibration patterns using 10 motors on an adaptive textile belt. This piece is again, genderless

Figure 2: Touching you/me with my breath

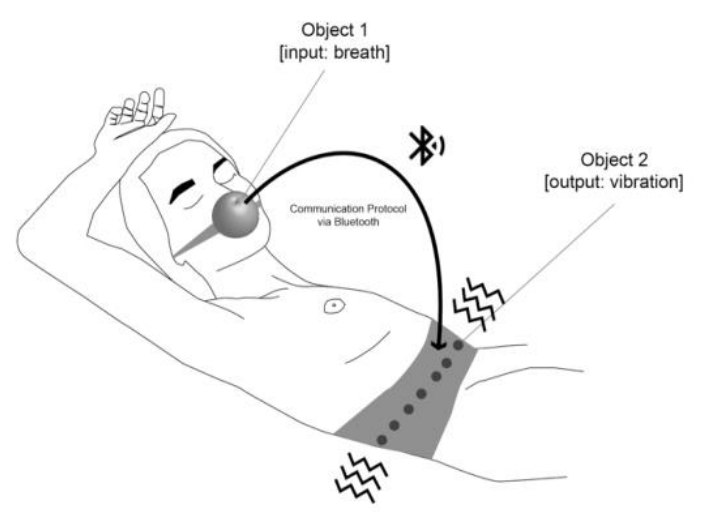

in nature, and seeks to subvert visuality as the primary mode of experience as it stimulates the body.

\subsection{Ardourino}

Ardourino by Kristin Weissenberger, Günter Seyfried from Pavillon35 \& Doris Roth from [kat]alab is an environmentally sensitive hydrogel which is reactive to electromagnetism.

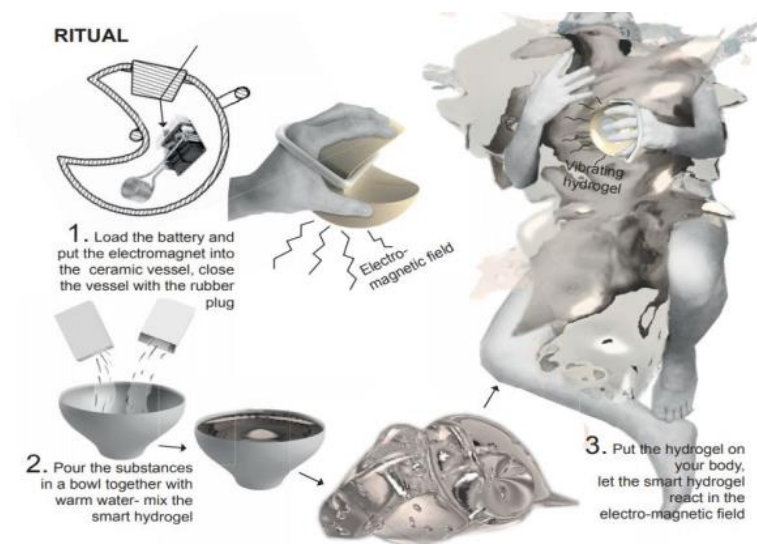

Figure 3: Ardourino

Ceramic vessels transfer the hydrogel on to the body, and an electromagnetic field is applied, activating the gel and creating sensations on the body.

\section{Discussion}

Our overall ambition is to advance the vision of the future of design, form and function of technologies designed for sex and pleasure and help mediate autonomous and non-binary articulations of desire and the machine. Entering the workshops, we came with a framing of what non-binary sex objects might be. The first workshop informed us that pleasure was much more interesting a term than sex, and extends to pleasure of the body, learning about the body, and experiencing the body. In workshop 2, we heard many ideas for how this might happen, both experiencing the body and experiencing new sensations, associations and having new experiences in new contexts.

There is an interest from artists, designers, academics, hackers, creatives and others to develop new concepts entirely about how we relate to pleasure and to our bodies. This move from sex to pleasure was of vital importance. Before we began the first workshop we had many discussions about what exactly disturbed us about this area, what needed to change. Besides our feminist and hacker approaches, we knew that sex extends beyond genital based pleasure. We developed the presentation we showed to the workshops to showcase these thought processes, asking: what other forms could pleasure take, and must it always be sexual in nature?

We see the three projects which emerged from this process and the upcoming Kit Zero as representations of the variety of forms future pleasure objects might take and we hope that the platform we develop can provide space for others to engage in this debate and create their own future 
pleasure objects. These kits represent, and offer an opportunity to explore how sex, or pleasure objects dictate what kind of sex we have and what sex and pleasure means to us as individuals. The kits enables users to explore their own sensitivity, to get inspired by a non-essentialist notions of gender and to tinker with a wide range of materials and technologies to extend norm-regulated (normative) body practices.

\section{CONCLUSION}

In this paper we document how our speculative concept of a future pleasure object emerged from three DIY workshops held in Vienna and Copenhagen. Based on these workshops our focus shifted from alternative and DIY forms of sex toys to a less genital-centered and simultaneously more sensation-based approach to bodily exploration and pleasure.

We situate our research in the feminist 3rd wave movement which fosters awareness of one's own desires, claims gender to be non-binary and embraces sexuality as part of our everyday lives.

We present three artistic works which emerged from these workshops, Text Me, Touching you/me with my breath, and Ardourino. All three reflect the discussions about the need for a deeper engagement with the participants' personal and intimate needs and desires. These three works act as beta DIY kits, alongside our presented future work: Kit Zero which provides sensors and actuators to begin forming one's own kit for exploration, will become part of an online platform, offering DIY-kits co-created with artists to help explore their own concepts and understand of pleasure.

This work acts as a starting point, inviting others to join our research and contribute to future pleasure objects.

\section{REFERENCES}

Ahmed, S., 2017. Living a feminist life. Duke University Press.

Barad, Karen, Kvinder, Køn \& Forskning 12 NR. 1-2 2012, p.12.

Bardzell, J. and Bardzell, S. (2011) "Pleasure is Your Birthright": Digitally Enabled Designer Sex Toys as a Case of Third-Wave $\mathrm{HCl}^{\prime}$, in Proceedings of the SIGCHI Conference on Human Factors in Computing Systems (CHI 2011), pp. 257-266. doi: cg75kh.

Bardzell, S. (Indiana U. (2010) 'Feminist $\mathrm{HCl}$ : Taking Stock and Outlining an Agenda for Design',
Proceedings of the 28th International Conference on Human Factors in Computing Systems, pp. 13011310. doi: $10.1145 / 1753326.1753521$.

Bdeir, A. (2018) LittleBits Synth. Ayah Bdeir. Available from: https://shop.littlebits.com/products/synth-kit [last accessed June 14]

Bjørner, T. 2015. Qualitative methods for Consumer Research, Hans Reitzels Forlag.

Bødker, S. (2006) 'When second wave $\mathrm{HCl}$ meets third wave challenges', Proceedings of the 4th Nordic conference on Human-computer interaction changing roles - NordiCHI '06, (October), pp. 1-8. doi: $10.1145 / 1182475.1182476$.

Blythe and Jones. 2004. Human computer (sexual) interactions. interactions 11, 5 (September 2004), 75-76.

DOI=http://dx.doi.org.zorac.aub.aau.dk/10.1145/10 15530.1015570.

Boer, L., Cahill, B. and Vallgårda, A., 2017, June. The Hedonic Haptics Player: A Wearable Device to Experience Vibrotactile Compositions. In Proceedings of the 2016 ACM Conference Companion Publication on Designing Interactive Systems (pp. 297-300). ACM.

Butler, J., 1997. Gender is burning: Questions of appropriation and subversion. Cultural Politics, 11, pp.381-395.

Butler, J., 2005. Giving an account of oneself. Oxford University Press.

Butler, J., 2011. Gender trouble: Feminism and the subversion of identity. Routledge.

Comingle. 2018. Comingle OSSex. Available from: http://www.comingle.io/OSSex/ [12.06.2018].

de la Bellacasa, M.P., 2017. Matters of care: Speculative ethics in more than human worlds. University of Minnesota Press.

Dewey-Hagborg, H. (2014) Stranger Visions. Heather Dewey-Hagborg. Available from: http://deweyhagborg.com/projects/stranger-visions [last accessed June 14].

Diefenbach, S., Kolb, N. and Hassenzahl, M., 2014, June. The'hedonic'in human-computer interaction: history, contributions, and future research directions. In Proceedings of the 2014 conference on Designing interactive systems (pp. 305-314). ACM. 
Eaglin, A. and Bardzell, S., 2011, May. Sex toys and designing for sexual wellness. In $\mathrm{CHI} 11$ Extended Abstracts on Human Factors in Computing Systems (pp. 1837-1842). ACM.

Foucault, M., 1990. The history of sexuality: An introduction, volume I. Trans. Robert Hurley. New York: Vintage.

Gaver, W. (2012) What should we expect from research through design?. In Proceedings of the SIGCHI Conference on Human Factors in Computing Systems (CHI '12). ACM, New York, NY, USA, 937-946. Available from: http://dx.doi.org.zorac.aub.aau.dk/10.1145/220767 $\underline{6.2208538}$ [last accessed June 14]

Gislev, Kjærsgaard, (Trans)forming Knowledge and Design Concepts in Design Workshops in Design Anthropology - Theory and Practice, Gunn, Otto \& Smith, 2013, p. 51.

Gunn, Otto \& Smith, Design Anthropology - Theory and Practice. In Gislev, Kjærsgaard, (Trans)forming Knowledge and Design Concepts in Design Workshops in Design Anthropology - Theory and Practice, Gunn, Otto \& Smith, 2013 p. 4.

Haraway, D., 1991. A cyborg manifesto. New York, p.150.

Hassenzahl, M., Eckoldt, K., Diefenbach, S., Laschke, M., Len, E. and Kim, J., 2013. Designing moments of meaning and pleasure. Experience design and happiness. International Journal of Design, 7(3).

Homewood, S. and Heyer, C. (2017) 'Turned on/turned off: Speculating on the microchip-based contraceptive implant', in DIS 2017 - Proceedings of the 2017 ACM Conference on Designing Interactive Systems. doi: 10.1145/3064663.3064726.

Huta, V. and Ryan, R.M., 2010. Pursuing pleasure or virtue: The differential and overlapping well-being benefits of hedonic and eudaimonic motives. Journal of Happiness Studies, 11(6), pp.735-762.

Hyunjoo Oh, Sherry Hsi, Kristof Klipfel, and Mark D. Gross. 2017. Paper Machines. In Proceedings of the Eleventh International Conference on Tangible, Embedded, and Embodied Interaction (TEI '17). ACM, New York, NY, USA, 771-774. DOI: https://doi-

org.zorac.aub.aau.dk/10.1145/3024969.3025050.

Jun Sik (Jason) Kim. 2013. Plus minus: passive education of basic circuitry through DIY product design. In Proceedings of the 12th International Conference on Interaction Design and Children (IDC '13). ACM, New York, NY, USA, 557-560.
DOI=http://dx.doi.org.zorac.aub.aau.dk/10.1145/24 85760.2485864

[kat]alab, 2018. Available from: https://katalab.wixsite.com/de-home/en-home [12.06.2018]

Kim, J. (2013) Plus minus: passive education of basic circuitry through DIY product design. In Proceedings of the 12th International Conference on Interaction Design and Children (IDC '13). ACM, New York, NY, USA, 557-560. Available from: http://dx.doi.org.zorac.aub.aau.dk/10.1145/248576 $\underline{0.2485864}$ [last accessed June 14]

Klemmer, S. R., Hartmann, B., Takayama, L. (2006) How bodies matter: five themes for interaction design. In Proceedings of the 6th conference on

Designing Interactive systems (DIS '06). ACM, New York, NY, USA, 140-149.Available from: http://dx.doi.org/10.1145/1142405.1142429 [last accessed June 14]

LittleBits Synth, 2018. Available from: https://shop.littlebits.com/products/synth-kit [12.06.2018]

Lo, J., Jung, D., Lin, L., Wong, N., Bui, D., Paulos, E. (2016) Skintillates: Designing and Creating Epidermal Interactions. In Proceedings of the 2016 ACM Conference on Designing Interactive Systems (DIS '16). ACM, New York, NY, USA, 853-864. Available from: https://doi.org/10.1145/2901790.2901885 [last accessed June 14]

Mekler, E.D. and Hornbæk, K., 2016, May. Momentary pleasure or lasting meaning?: Distinguishing eudaimonic and hedonic user experiences. In Proceedings of the $2016 \mathrm{CHI}$ Conference on Human Factors in Computing Systems (pp. 4509-4520). ACM.

Mohanty, C., 2003. Feminism without Borders: Decolonizing Theory, Practicing Solidarity. Duke University Press.

Nagels, S., Ramakers, R., Luyten, K., Deferme, W. (2018) Silicone Devices: A Scalable DIY Approach for Fabricating Self-Contained Multi-Layered Soft Circuits using Microfluidics. In Proceedings of the $2018 \mathrm{CHI}$ Conference on Human Factors in Computing Systems (CHI '18). ACM, New York, NY, USA, Paper 188, 13 pages.

Oh, H., Hsi, W., Klipfel, K., Gross, M.D. (2017) Paper Machines. In Proceedings of the Eleventh International Conference on Tangible, Embedded, and Embodied Interaction (TEI '17). ACM, New York, NY, USA, 771-774. A 
Pechblenda. (2015) GynePunk, the cyborg witches of DIY gynecology Ewen Chardronnet. Available from:

http://www.makery.info/en/2015/06/30/gynepunkles-sorcieres-cyborg-de-la-gynecologie-diy/ [last accessed June 14].

Perner-Wilson, H., Buechley, L., Satomi, M. (2010) Handcrafting textile interfaces from a kit-of-noparts. In Proceedings of the fifth international conference on Tangible, embedded, and embodied interaction (TEI '11). ACM, New York, NY, USA, 61-68. Available from:

http://dx.doi.org/10.1145/1935701.1935715 [last accessed June 14]

Pavillon35. 2018. Available from: http://pavillon35.polycinease.com/ [12.06.2018]

Reis, Patricia J. 2018. Available from: http://www.patriciaireis.com/ [12.06.2018]

Sparkfun Kits, 2018. Robotic Kits. Available from: https://www.sparkfun.com/categories/181

[12.06.2018]

Tomasello, G. (2018) Future Flora Giulia Tomasello.Available from:

https://gitomasello.com/Future-Flora [last accessed June 14].

Tsang, M. (2016) Estrofem Lab: Estrogen Geeking. MAGGIC Mary Tsang. Available from: http://www.maggic.000/Estrofem-Lab-2016 [last accessed June 14]. 